of the Journal of the Society appeared (Journal of the Malacological Society of Australia, No. 1, September 1957. Pp. 52. 158.). This consists of 52 pages almost identical in size with those of the Proceedings of the Malacological Society, six of them utilized as plates. It contains eleven articles, of which the longest two deal with opisthobranchs, and the author of the second, Robert Burn, has set an example which it is hoped will be followed by subsequent writers, of presenting type specimens to a national museum. One of the patrons of the Society is Prof. R. Tucker Abbott of the Academy of Natural Sciences, Philadelphia, a very fitting selection in view of the old association between the Academy and Australian malacologists. The paper, printing and general format of the journal are very good and it is a praiseworthy start. We should like to wish the Society and its journal every success. No. 1 is priced $15 s$. but there is no indication of how frequently it will appear or of the steps necessary to become a member of the Society. Doubtless these details can be obtained from the Secretary, 351 Glenferrie Road, Malvern, Melbourne, Australia.

\section{Reptile Faunules}

Investigations by Donald Baird in quarries in the Delaware valley near Milford, New Jersey, have yielded three faunules of reptile footprints at three horizons of the upper Brunswick formation (Newark series, Upper Triassic). Each determinable species was analysed by comparison of outlines printed from latex moulds of all adequately preserved specimens (Bulletin of the Museum of Comparative Zoology at Harvard College, 117, No. 5 ; 1957). Body proportions and locomotor habits were deduced from trackways and the pedal skeletons were reconstructed from the arrangements of articular swellings in the footprints. Comparison with other Triassic footprints furnished information on faunal distribution and stratigraphic correlation; comparison of the restored skeletons with those of Triassic reptiles served to elucidate and enlarge the known Brunswick fauna.

\section{Plankton and the Herring Fisheries}

ThE pioneer investigations of Sir Alister Hardy into the relation between herrings and the plankton that forms their food have been continued by $\mathrm{Mr}$. R. S. Glover and his colleagues of the Edinburgh Oceanographic Laboratory. The improved plankton 'indicator', which takes samples from ships at speeds up to $8 \frac{1}{2} \mathrm{knots}$, is now a simple and elegant instrument for detailed surveys, as two recent publications demonstrate. Results of nine years sampling, by fishing boats and research vessels, over the summer fishing grounds off the north-east coast of Scotland are described by Mr. Glover (Bulletins of Marine Ecology (formerly Hull Bulletins of Marine Ecology), 5 (39); December 1957. The Planktonic Environment of the Herring. By R. S. Glover. Pp. 1-43+plates 1-8. Edinburgh : Scottish Marine Biological Association, 1957. 13s.). The spatial and temporal distribution of the commoner organisms taken by the indicators are shown by means of contoured charts, and commented on. It is suggested that changes in the plankton during 1951-54-a predominance of more or less oceanic species-were related to changes in the volume and direction of flow of Atlantic water entering the North Sea. Accompanying changes in the fishery, in particular the occurrence of increased catches on the southern grounds and a failure of the
Shetland fishery, appear to have been related to the plankton changes. However, Mr. Glover points out that non-feeding fish are caught during the second half of the season (July and August), and more subtle environmental factors than food may therefore have influenced the shoaling of the fish. A study of the plankton in the area of the autumn fishery off the south-west coast of Iceland by Herr J. Jakobsson (Rit Fiskideildar, 2 (5) : A Study of the PlanktonHerring Relationship. By Jakob Jakobsson. Pp. 26. Reykjavik: Atvinnudeild Háskolans: Fiskideild, 1958) shows that this fishery conforms with other feeding fisheries in that shoals aggregate in areas rich in zooplankton, chiefly the copepod Calanus and euphausids. Correlation between echo-sounder traces of herring and concentrations of euphausids was obtained only with the plankton indicator, few euphausids being caught by means of a vertical Hensen tow-net. This emphasizes the superiority of high-speed samplers for the purpose.

\section{Complementary Action of Gibberellic Acid and Auxin}

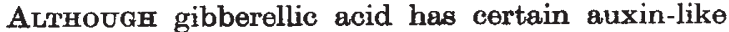
activities, it differs from auxin in many respects. P. W. Brian and H. G. Hemming (Annals of Botany, N.S., 22, 1 ; 1958) have now shown that gibberellic acid induced extension of green pea-stem sections in light only if an auxin was also present. Of the auxins tested 3-indolylacetic acid, 2-methyl-4-chlorophenoxyacetic acid, $2: 4$-dichloro-phenoxyacetic acid and 1-naphthylacetic acid were effective in increasing extension of sections and in eliciting a response to the acid. Excised internodes from plants pre-treated with gibberellic acid extended appreciably faster in vitro than those from untreated plants only if an auxin was supplied in the incubation medium. This and other evidence suggests that in the intact plant gibberellic acid elicits a growth-response only in the presence of auxin. By comparing growth-rates of excised internodes in vitro and of intact internodes in vivo under comparable conditions, using untreated plants and plants pre-treated with gibberellic acid, evidence has been obtained that in untreated plants growth-rate is somehow limited to a level below that made potentially possible by the endogenous auxin supply; treatment with gibberellic acid appears to release the plant from this state of inhibition. Growth of intact pea internodes is considered to be regulated by a three-factor system, consisting of auxin, an inhibitory system, and a hormone with physiological properties similar to those of gibberellic acid.

\section{Diffusion in the Atmosphere}

IT is remarkable, considering the fundamental nature of the problem, that no discussion of the dynamics of plumes formed by natural convection from point and line sources of heat appeared before 1941, when W. Schmidt produced his now wellknown 'mixing length' treatment. In recent years the problem has attracted much attention because of its importance in connexion with atmospheric pollution. The greater part of a recent monograph (Koninklijk Nederlands Meteorologisch Instituut, De Bilt. Mededelingen en Verhandelingen. Nr. 68 : On the Diffusion of Stack Gases in the Atmosphere. By F. H. Schmidt. Pp. 60. 'S-Gravenhage : Staatsdrukkerij- en Uitgeverijbedrijf, 1957. 5 florins) is concerned with a discussion of the solutions derived by W. Schmidt, Sutton, Priestley and Ball, Morton, Taylor and Turner and by the author. Considerable 